Papers and Proceedings of the Royal Society of Tasmania, Volume 113, 1979.

(ms. received 28.7.1978)

\title{
A NOTE ON THE ANNUAL VARIABILITY OF SOLAR RADIATION AT HOBART AIRPORT. TASMANIA
}

by M. Nunez

University of Tasmania

(with one table and one text figure)

\section{ABSTRACT}

NUNEZ, M., 1979 (20 vii): A note on the annual variability of solar radiation at Hobart Airport, Tasmania. Pap. Proc. R. Soc. Tasm., 113: 1-3. ISSN 0080-4703. Department of Geography, University of Tasmania, Hojart, Tasmania, Australia.

The annual variability of solar radiation at Hobart airport is calculated. The implication of this variability for the solar energy potential of Tasmania is discussed.

There is at present an increasing awareness of the potential for the use of solar energy in domestic and industrial application. An important facet in any practical use of solar energy is the day to day variability of the incoming solar radiation. This factor has largely been ignored in geographical assessments of solar radiation as they mostly deal with climatological monthly averages (Hounam 1963; Paltridge and Proctor 1976).

To illustrate the magnitude of the variability, ten years of daily solar radiation data (1968-1977) collected over Hobart airport were used in this analysis. The data was obtained from the Australian Bureau of Meteorology which maintains a network of solar energy monitoring stations throughout Australia. The data was collected by a pyranometer. At any one instant of time the instrument produces a millivolt signal proportional to all direct and diffuse solar energy incident on a unit horizontal surface per unit time (Robinson 1966). Integrating the signal over a day yields the daily flux which is commonly expressed in units of Mega-Joules per metre ${ }^{2}$ per day $\left(\mathrm{MJm}^{-2} \mathrm{day}^{-1}\right)$.

Cloudless conditions were investigated first since solar radiation under these conditions would represent a convenient upper boundary to the energy received at the surface. Inspection of these days gave a smooth curve for the daily distribution of solar radiation over the year (fig. 1). All data were then analyzed by grouping together daily totals of solar radiation for each day of the year with its counterparts. The mean and standard deviation were then calculated for each group and are shown in figure 1. A ten day running mean through both data sets shows a maximum standard deviation in early January which exceeds $6 \mathrm{MJm}^{-2}$ day-1 or $28 \%$ of the incoming solar radiation. This value decreases with solar elevation reaching a minimum of $1.6 \mathrm{MJm}^{-2}$ day $^{-1}$ in late June which represents approximately $35 \%$ of the incoming radiation.

The daily variability is dominantly a function of cloud cover, and to a lesser extent wil1 depend on atmospheric water vapour and dust content (Davies et a. . 1975). Therefore it is possible to represent the cloudless solar radiation as a smooth curve which is usually within $5 \%$ of the observed daily values. On the other hand solar radiation depletion by clouds can be extremely variable since it depends on such cloud properties as type, amount, thickness, liquid water and water vapour content, etc. 


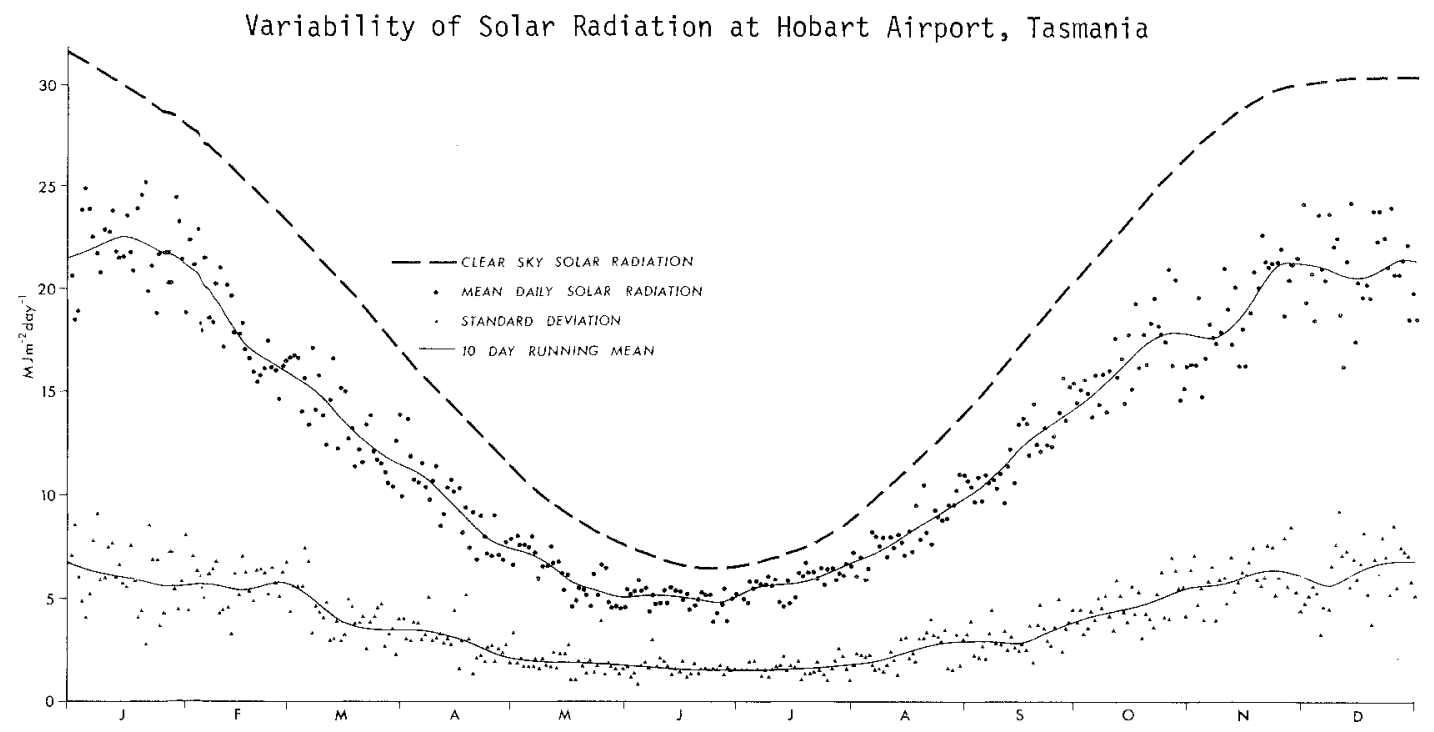

FIG. 1. - Daily solar radiation statistics for Hobart Airport (1968-1977).

It is evident from the above results that the magnitude of the solar radiation variability imposes doubts on the usefulness of monthly average data in solar energy applications. More relevant information can be obtained from a frequency distribution of the solar energy received. Table 1 gives the average number of days in a month with energy fluxes along selected interva1s. The intervals are in units of $25 \%$ of the mean monthly solar radiation $\left(\mathrm{K}_{\mathrm{c}}\right)$. Results show that there is a maximum of 8.4 days in May and a minimum of 6.0 days in January and October when the solar energy is less than $\frac{3}{4}$ of the mean monthly value. Clearly the above represent significant portions of the month which are considerably below the monthly average figure. Perhaps it would be more useful to define a "working" value of solar radiation which would be lower than $90 \%$ of the daily values in a given month (the ten percentile value). Inspection of Table 1 shows that $\frac{1}{2}$ of the mean monthly radiation $K_{c}$ could be considered as a ten percentile value in eleven months, although it is marginal for the month of March.

In some cases, a solar energy storage system will respond not only to daily events but to processes that occurred in the past as well. This kind of storage system would minimize the problem of collecting little energy on an overcast day in a solar climate which is highly variable on a daily basis. Unfortunately this does not seem to be the case for Hobart airport since running a two day moving average on the. data does not cause large changes in the number of days in the low end of the energy spectrum. On average, the number of days with energy less than $\frac{3}{4}$ of $K_{c}$ decreases only by 1 to 2 days for most months. A likely explanation for this effect is the persistence that exists in the weather systems which deplete solar radiation.

It should be kept in mind that the above data analysis refers to one location and that serious errors could arise if the results are applied elsewhere. This is particularly relevant in the Tasmanian context where climatic gradients are large and daily solar radiation variability could change significantly throughout the island. For example, two stations may have the same mean solar radiation but different frequency distribution in their solar energy receipt. A west coast location may be marked by sharp changes in daily cloud cover (clear to overcast) with a marked persistence in each state, while an east coast location may exhibit a more even cloud cover regime. It is evident that solar energy storage would be a much more serious problem in the west coast. 
M. Nunez

TABLE 1

FREQUENCY DISTRIBUTION OF SOLAR ENERGY FOR HOBART AIRPORT (1968-1977)

( $N$ refers to the average number of days in a month with a given energy interval. Energy intervals are expressed as per cent of the mean monthly value $\mathrm{K}_{\mathrm{c}}$ )

Daily solar radiation (cloudless), MJm-2 day ${ }^{-1}$ $30.0 \quad 25.4 \quad 20.2 \quad 14.1 \quad 9.3 \quad 6.5 \quad 7.6 \quad 11.6 \quad 18.2 \quad 24.7 \quad 29.4 \quad 30.8$

Daily solar radiation $K_{c}$ (all days), $\mathrm{MJ}^{-2} \mathrm{day}^{-1} \mathrm{C}$

$0 \leq \mathrm{K}_{\mathbf{i}}<0.25 \mathrm{~K}_{\mathrm{c}}, \mathrm{N}:$

$\begin{array}{lllllllllllll}22.0 & 18.1 & 13.6 & 9.3 & 6.1 & 5.0 & 5.8 & 8.2 & 12.2 & 16.5 & 19.3 & 21.0\end{array}$

$\begin{array}{lllllllllllllll}0.25 \mathrm{~K}_{\mathrm{c}} \leq \mathrm{K}_{\mathrm{i}}<0.50 & \mathrm{~K}_{\mathrm{c}}, \mathrm{N}: & 1.7 & 2.3 & 2.4 & 2.4 & 2.2 & 1.8 & 2.3 & 1.7 & 1.6 & 2.1 & 2.8 & 1.7\end{array}$

$0.50 \mathrm{~K}_{\mathrm{c}} \leq \mathrm{K}_{\mathrm{i}}<0.75 \mathrm{~K}_{\mathrm{c}}, \mathrm{N}: \quad \begin{array}{lllllllllllll}0.8 & 3.9 & 3.9 & 4.7 & 6.1 & 5.9 & 4.1 & 5.5 & 4.3 & 3.6 & 3.8 & 4.8\end{array}$

$0.75 \mathrm{~K}_{\mathrm{c}} \leq \mathrm{K}_{\mathrm{i}}<1.00 \mathrm{~K}_{\mathrm{c}}, \mathrm{N}: \quad \begin{array}{lllllllllllll}0.6 & 4.6 & 7.3 & 7.3 & 7.5 & 6.3 & 8.3 & 7.0 & 8.8 & 8.0 & 6.6 & 6.6\end{array}$

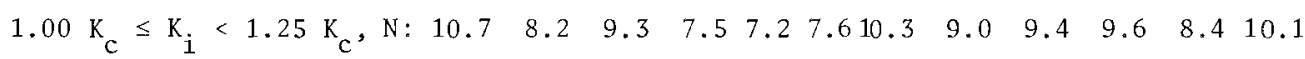

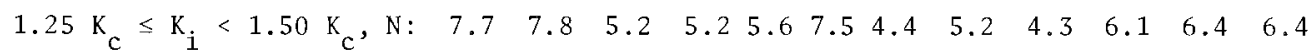

$\begin{array}{llllllllllllllll}1.50 \mathrm{~K}_{\mathrm{C}} \leq \mathrm{K}_{\mathrm{i}}<1.75 \mathrm{~K}_{\mathrm{C}}, \mathrm{N}: & 0 & 0.5 & 2.2 & 2.3 & 2.0 & 0.3 & 1.0 & 1.7 & 1.5 & 1.1 & 1.4 & 0.7\end{array}$

$1.75 \mathrm{~K}_{\mathrm{c}} \leq \mathrm{K}_{\mathrm{i}}<2.00 \mathrm{~K}_{\mathrm{c}}, \mathrm{N}: \quad \begin{array}{llllllllllllll}0 & 0 & 0 & 0.1 & 0.3 & 0.3 & 0.2 & 0.1 & 0 & 0.2 & 0.1 & 0\end{array}$

The above example is only speculative since no monitoring network of solar radiation exists in the state. In fact Hobart airport is the only station in Tasmania where solar data is collected by the Bureau of Meteorology. The establishment of such a network would represent a first step in the assessment of the solar energy potential for the state.

\section{ACKNOWLEDGEMENTS}

The author gratefully acknowledges the cooperation of the Australian Bureau of Meteorology who supplied the data. Thanks are also due to Mrs. K. Morris who did the drawing and Miss T. Flannagan who typed the manuscript.

\section{REFERENCES}

Hounam, C.E., 1963: Estimates of solar radiation over Australia. Australian Meteorological Magazine, 43: 1-14.

Davies, J.A., Schertzer, W. and Nunez, M., 1975: Estimating global solar radiation. Boundary Layer Meteorology, 9: 33-52.

Paltridge, G.W. and proctor, D., 1976: Monthly mean solar radiation statistics for Australia. Solar Energy, $18(3): 235-243$.

Robinson, G.D., 1966: SOLAR RADIATION. Elseviex, 347 pp. 